\title{
PEMBUATAN MASKER PEEL-OFF KUNYIT UPAYA KEMANDIRIAN EKONOMI KELUARGA DI KELURAHAN KAHURIPAN KECAMATAN TAWANG KOTA TASIKMALAYA
}

\author{
Asep Kuswandi ${ }^{1}$, Asep Abdul Rahman ${ }^{1}$ dan Nunng Yulia ${ }^{1}$ \\ ${ }^{1}$ Poltekkes Kemenkes Tasikmalaya \\ asepkuswandi@yahoo.com,
}

Diterima: 30 Oktober 2018

Direvisi: 10 November 2018

Diterbitkan:07 Januari 2019

\begin{abstract}
Community empowerment is one of the important aspects that must be done at this time because community powerlessness is one source of national problems currently being faced. The Ministry of Health Tasikmalaya Health Polytechnic is located in Kahuripan Sub-District, Tawang, Tasikmalaya City. Kahuripan Village was chosen as the location of community service because this location was one of the villages that received PKH (Hope Family Program) assistance. The large number of people who are recipients of $\mathrm{PKH}$ is one indicator of the absence of family economic independence that can reduce poverty and improve the quality of human resources. So that we hope that with the activities of the Community Partnership Program (PKM) this can reduce the number of PKH recipients in particular and can improve the economic level of the Kahuripan Village community in general. Based on these problems, the question is obtained, namely how to grow entrepreneurial spirit, commitment, knowledge and skills of cadres to make turmeric products that have high economic value. The expected outcome target is to foster entrepreneurial spirit, the products produced, and information on business capital loans. The methods used are group formation cadres, placement tests to understand the material to be delivered (50\% of participants have not yet used turmeric for years), 5-hour workshops (about family herbs, motivation, processing turmeric as peel off masks, production assistance and monitoring evaluation for program sustainability The results of the activity show that the community is able to produce peel off masks as cosmetic ingredients that have economic value.
\end{abstract}

Keywords: Economic Independence, Processing of Turmeric, Mask Peel Off

\begin{abstract}
ABSTRAK
Pemberdayaan masyarakat merupakan salah satu aspek penting yang harus dilakukan pada saat ini karena ketidakberdayaan masyarakat menjadi salah satu sumber dari permasalahan nasional yang sedang dihadapi saat ini. Poltekkes Kemenkes Tasikmalayater letak di Kelurahan Kahuripan Kecamatan Tawang Kota Tasikmalaya. Kelurahan Kahuripan dipilih sebagai lokasi pengabdian kepada masyarakat karena lokasi ini merupakan salah satu kelurahan yang banyak mendapatkan bantuan PKH (Program Keluarga Harapan). Banyaknya jumlah masyarakat yang penerima PKH ini menjadi salah satu indikator belum adanya kemandirian ekonomi keluarga yang dapat menanggulangi kemiskinan dan peningkatan kualitas sumber daya manusia. Sehingga kami berharap dengan adanya kegiatan Progran Kemitraan Masyarakat (PKM) ini dapat menurunkan angka penerima PKH secara khusus dan dapat meningkatkan taraf ekonomi masyarakat Kelurahan Kahuripan pada umumnya. Berdasarkan permasalahan tersebut didapatkan pertanyaan, yaitu bagaimanakah menumbuhkan jiwa kewirausahaan, komitmen, pengetahuan dan keterampilan kader untuk membuat produk kunyit yang memiliki nilai jual tinggi secara ekonomi Target luaran yang diharapkan adalah menumbuhkan jiwa kewirausahaan, adanya produk yang dihasilkan, dan adanya informasi pinjaman modal usaha. Metode yang digunakan yaitu pembentukkan kelompok kader, placement test untuk pemahaman materi yang akan disampaikan (50\% peserta belum tahun pemanfaatan kunyit), workshop 5 jam (tentang tanaman obat keluarga, motivasi, pengolahan kunyit sebagai masker peel off, pendampingan produksi dan
\end{abstract}


monitoring evaluasi untuk keberlanjutan program. Hasil kegiatan menunjukkan bahwa masyarakat mampu memproduksi masker peel off sebagai bahan kosmetik yang memiliki nilai ekonomis.

Kata Kunci : Kemandirian Ekonomi, Pengolahan Kunyit, Masker Peel Off

\section{PENDAhULUAN}

Kunyit memiliki banyak bagi kehidupan manusia. Namun tidak semua mengenali dan memahami manfaat kunyit tersebut. Kunyi bisa bermanfaat baik sebagai bahan makanan maupun sebagai obat serta kosmetik. Hasil penelitian menunjukkan ada beberapa manfaat kunyit terutama bagi kulit. Manfaat terhadap kulit diantaranya telah diteliti bahwa dengan aplikasi emulsi yang mengandung $12 \%$ dan 25\% ekstrak kunyit menunjukkan warna kulit tetap terjaga meskipun emulsi telah dibersihkan [1]. Analisis sensorik menunjukkan bahwa emusli yang diujikan dengan ekstrak curcuma memiliki dampak yang signifikan terhadap kehalusan, penyebaran, penyerapan dan efikasi kulit. Kunyit juga sering digunakan oleh masyarakat sejak zaman dahulu sebagai lulur. Penelitian telah melakukan dengan mengkombinasikan simplisia kunyit (Curucuma domestica L) dengan temu giring (curcuma heyneana), kulit kayu manis (Cinnamomum Bunani nees) BI), daun kemuning (Murraya paniculata $(L)$ dan kayu cendana (Sanatalum alum) [2,3]. Hasil penelitian tersebut menyebutkan bahwa kunyit memiliki antioksidan selain anti tumor dan udah diserap oleh kulit. Selain sebagai bahan kosmetik, ternyata kunyit juga bisa sebagai bahan pewarna alami dan terbebas dari sifat karsinoggen seperti pewarna kimia yang berededar di pasaran [3]. Bahkan, kunyit bisa sebagai pereduksi formalin yang ada pada tahu [5]. Mengapa kunyit sangat baik bagi kecantikan atau kulit, karena kulit mengandung minyak astriri 3-5 \% (senyawa d-alfapelandren $1 \%$, d-sabinen $0,6 \%$, cineol $1 \%$, borneol $0,5 \%$, zingiberen $25 \%$, timeron 58\%, seskuiterpen alcohol 5,8\%, alfa-atlanton, gamma-atlanton, turneron, simen, dan artomeron). Kandungan lainnya yaitu kurkurmin $0,36 \%-6,5 \%$, zat pati 40-50\%, zat pahit, selulosa, mineral, vitamin dan resin/ dammar. Kegunaan dari kunyit diantaranya dibuat simplisia untuk minuman/ jamu, lulur (kosmeti), pil (obat), bumbu masak, zat pewarna makanan nasi/ lauk pauk dan textile $[3,6]$. Khasiat lain dari kunyit bagi manusia adalah sebagai antioksidan, penanganan inflamasi, gangguan metabolic, atritis, kecemasan dan hiperlipidemia [7].

Kegiatan pengabdian kepada masyarakat kesempatan di tahun ini adalah ingin mengajak masyarakat memahami, mengetahui dan mampu memberdayakan kunyit menjadi bahan kosmetik yang memiliki nilai ekonomis seperti hasil-hasil penelitian yang terdahulu. Metode kegiatan ini dengan teknik pendampingan dan partisipan. Tim pengabdian masyarakat melakukan kajian awal mengenai lokasi, pemahaman, melakukan pelatihan, melakukan pendampingan dan evaluasi/ monitoring sehingga dihasilkan suatu produk masker peel off kunyit yang siap diedarkan di pasaran. Hasil survey awal diketahui permasalahanpermasalahan sebagai berikut : manajemen usaha, produksi dan masalah modal usaha.

\section{METODE}

Metode kegiatan yang telah dilakukan meliputi upaya kerja sama lintas program dan lintas sektoral. Upaya kerja sama lintas program meliputi upaya melibatkan Puskesmas Kahuripan dan Dinas Kesehatan Kota Tasikmalaya. Sedangkan upaya lintas sektoral melakukan upaya pendekatan ke kelurahan Kahuripan, Kecamatan Tawang, Dinas Perindustrian dan Perdagangan, serta para tokoh masyarakat. Kegiatan selanjutnya adalah melakukan penyuluhan dan pelatihan dengan sasaran 20 orang ibu-ibu rumah tangga. Isi 
penyuluhan dan pelatihan meliputi : membangun jiwa kewirausahaan, kemananan produk kosmetik, produk masker peel off kunyi, dan informasi pemodalan perbankan.

\section{HASIL DAN PEMBAHASAN}

Berdasarkan hasil monitoring hasil Pengabmas 2018 di masyarakat kelurahan Kahuripan kecamatan Tawang Kota Tasikmalaya. Program Pengabdian Masyarakat berbasis Ipteks bagi Masyarakat (IbM) ini khalayak sasarannya adalah warga Kecamatan Tawang Kota Tasikmalaya yang membentuk kelompok dipimpin oleh kader kesehatan. Kegiatan ini merupakan kelanjutan sebagai upaya kesinambungan. Tahun 2016 merupakan kegiatan

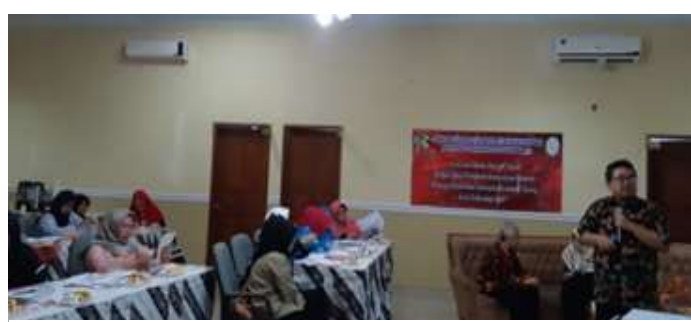

Gb. 1 Tim Pengabmasy memberikan pencerahan tentang keamanan Produk kosmetik upaya penanaman kunyit sedangkan tahun 2017 merupakan upaya pemanfaatan kunyit sebagai bahan serbuk untuk bahan jamu. Masih di lokasi yang sama, maka tahun 2018 merupakan tahun pembuatan masker peel off kunyit.

Kegiatan inti dilakukan dengan pembentukan kelompok kader. Tindak lanjut hasil pengabdian masyarakat tahun 2018 warga Kecamatan Tawang Kota Tasikmalaya dibentuk kelompok kader, salah satunya dibentuk kelompok kader kunyit yang nantinya akan menjadi kelompok tetap dalam melakukan produksi masker peel off kunyit.

Setelah terbentuk kelompok, sebelum masuk ke kegiatan penyuluhan, kelompok kader diberikan pertanyaan sebagai pretest untuk mengetahui sejauh mana pengetahun kader yang sudah dibentuk terhadap manfaat kunyit sebagai tanaman herbal. Hasil yang diperoleh 50\% warga belum mengetahui pemanfaatan kunyit sebagai bahan dasar pembuatan masker peel off yang bernilai ekonomi.

Selanjutnay adalah kegiatan workshop. Lama workshop berlangsung selama 5 jam. Peserta terdiri dari para warga kecamatan tawang yang bersedia mengikuti workshop dengan jumlah 6 orang. Pemateri terdiri dari 4 orang dosen Jurusan Farmasi Poltekkes Kemenkes Tasikmalaya, didampingi oleh 2 orang mahasiswa sebagai teknisi yang membantu dalam kegiatan workshop. Kegiatan workshop pertama adalah sosialisasi tentang penggunaan Tanaman Obat Keluarga (TOGA) khususnya tanaman kunyit sebagai bahan baku sediaan Farmasi dalam hal ini kosmetik yang dapat bernilai ekonomis sehngga dapat meningkatkan kesehatan masyarakat serta pemanfaatan kunyit

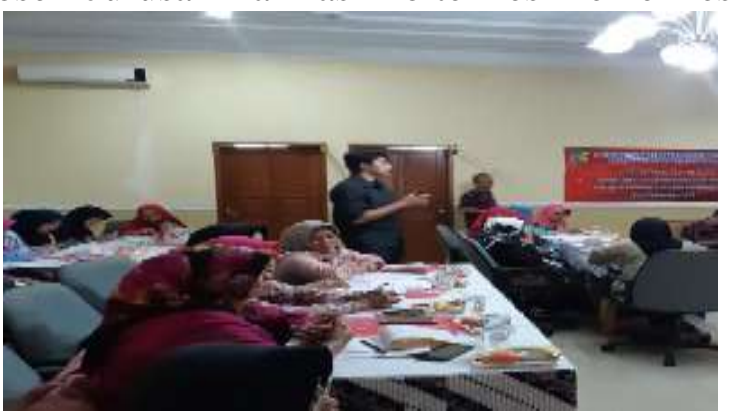
dalam upaya meningkatkan perekonomian masyarakat.Metode yang digunakan adalah dengan ceramah, diskusi,dantanyajawab menggunakan media LCD dan layar putih. Pembuatan Slideslide power point yang menarik dan menampilkan Video yang sesuai dengan tema agar

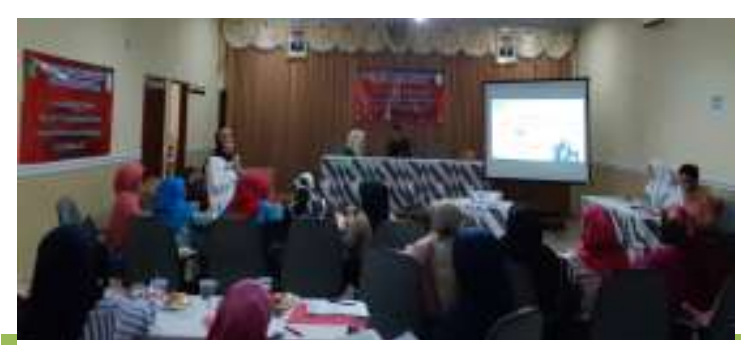
peserta sosialisasi lebih dapat memahami materi yang disajikan.

Pemberian motivasi kepada masyarakat tentang pemanfaatan bantuan pemerintah sebagai modal kegiatan produktif melalui metode ceramah, diskusi, dan tanyajawab. 
Kegiatan ini meningkatkan motivasi

kebersamaan dan komitmen.

han $\quad \begin{array}{r}\text { Pengola } \\ \text { kunyit }\end{array}$
secara sederhana untuk meningkatkan stabilitas kunyit dan menambah nilai jual secara

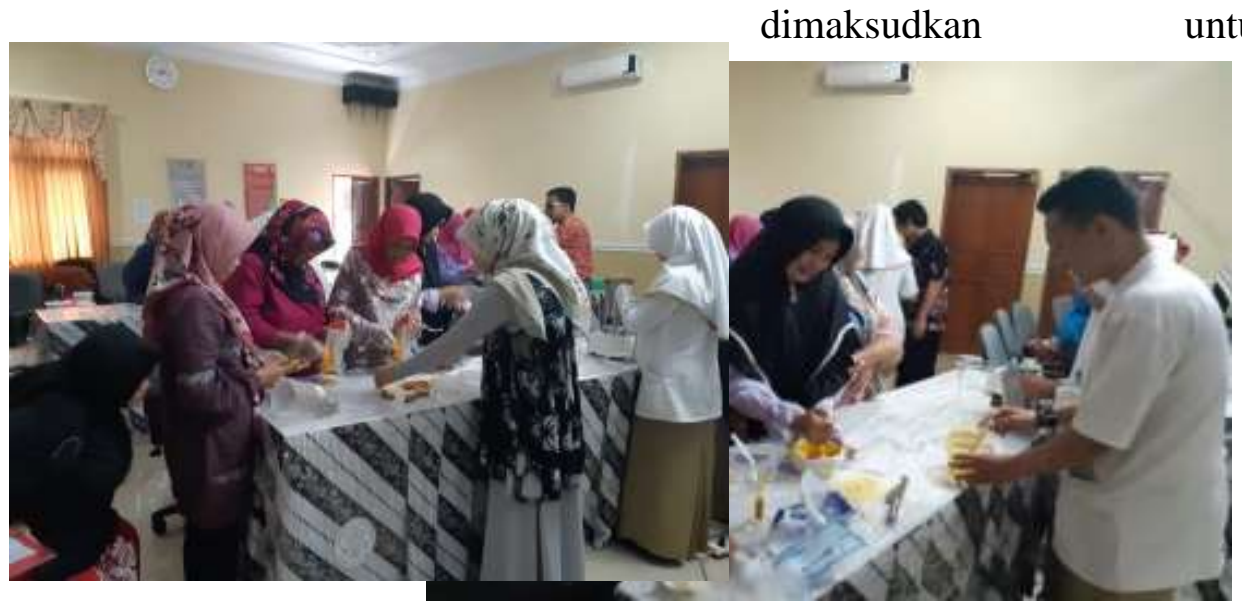

ekonomi dalam bentuk masker peel off. Pendampingan Produksi. Pendampingan produksi masker peel-off kunyit dilaksanakan nada tanggal 4 Oktoher 2018 dihantu oleh mahasiswa, kader yang datang seb Gb.4. Produksi masker peel off oleh warga dan mahasiswa. Igram

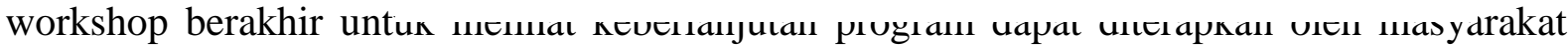
sasaran.

Hasil kegiatan pengabdian masyarakat tahun ini masyarakat khususnya kelompok kader kelurahan kahuripan kelompok kader kunyit sudah mengatahui fungsi kunyit sebagai tanaman herbal dan mampu memproduksi masker peel of yang tadinya kunyit difungsikan sebagai bumbu dapur saja, sekarang sudah bisa diproduksi menjadi bahan kosmetik yang

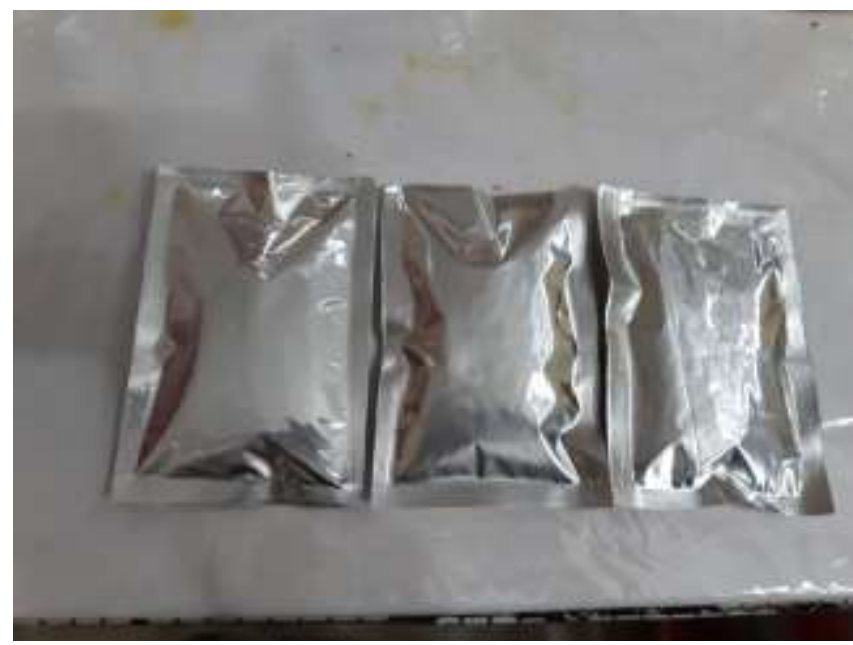
memiliki nilai ekonomis.

Kegiatan ini dipengaruhi oleh pendukung dan kendala. Faktor pendukung dalam melakukan pengabdian masyrakat tahun ini didukung oleh antusiasme dari kader, dukungan pemerintahan kecamatan Tawang. Sedangkan kendala yang didapat saat melaksanakan pengabdian masyarat ini adalah produksi masker peel-off kunyit memerlukan waktu yang cukup lama, jumlah kader yang mengikuti kegiatan tidak sesuai target karena dalam proposal target kader kolompok kunyit sebanyak 20 orang, sedangkan yang mengikuti kegiatan pengabdian secara konsisten hanya berjumlah 6 orang.

Kegiatan ini perlu dilakukan tindak lanjut agar bisa dijalankan di masyarakat. Program tindak lanjut dari pengabdian masyarakat tahun ini adalah perizinan Produk Kosmetika agar produk yang dibuat bisa dipasarkan

\section{SIMPULAN}

1. Warga kelurahan Kahuripan memiliki ilmu pengetahuan tentang pembuatan masker peel off dari bahan alam kunyit.

2. Warga kelurahan Kahuripan memiliki pengetahuan teknologi pengolahan bahan alam untuk pembuatan masker peel off. 
3. Warga kelurahan Kahuripan memiliki kemampuan mengemas produksinya dalam bentuk kemasan yang siap diedarkan.

\section{DAFTAR PUSTAKA}

[1] Arct, J, Ratz-Kyko, A, Mieloch, M, Witulska, "Evaluation of Skin Colouring Properties of Curcuma Longa Extract", Indian J Pharm Sci. 76(4):374-8 (2014)

[2] Sayuti, NA., Indiarto, AS., Suhendriyo, "Formulasi Hand \& Body Lotion Antioksidan Ekstrak Lulur Tradisional", Jurnal Terpadu Ilmu Kesehatan, 5:2 110-237 (2016)

[3] Ningtyas, G., " Uji Efektifitas Ekstrak Rimpang Kunyit (Curcuma domestica Val) dalam Mempercepat Proses Penyembuhan Luka Sayat pada Mencit (Mus musculus) Jantan" Universitas Muhammdiyah Surakarta (2017) (Tidak dipublikasikan)

[4] Azizah, B., Salamah, N., " Perbandingan Kadar Kurkumin Ekstrak Etanol dan Ekstrak Terpurifikasi Rimpang Kunyit” Jurnal Ilmiah Kefarmasian,, 3 : 1, 21 -30 (2013)

[5] Berlian, z., Pane, ER., Hartati, S, "Efektivitas Kunyit (Curcuma domestica) sebagai Pereduksi Formalin pada Tahu" Jurnal SainHeallth 1:1 (2017)

[6] Priyono, "Agribisnis Tanaman Obat Kunyit dan Lengkuas" Jurnal Inovasi Pertanian 9:2, 81 - 85 (2010)

[7] Hewlings, SJ and Kalman, DS,"Curcumin: A Review of Its' Effects on Human Health" Foods, 6:10, 92 (2017) 